\title{
Beternak Sapi: Sumber Pendapatan Alternatif pada Saat Kelapa Sawit Replanting
}

\author{
Beef Cattle Farming: Alternative Income Source during Palm Oil Replanting
}

\author{
Latifa Siswati $^{1 *}$, Rini Nizar ${ }^{1}$ dan Enny Insusanty ${ }^{2}$ \\ ${ }^{1}$ Fakutas Pertanian Universitas Lancang Kuning \\ ${ }^{2}$ Fakultas Kehutanan Universitas Lancang Kuning Pekanbaru \\ *Corresponding e-mail : latifasiswati@unilak.ac.id
}

\begin{abstract}
This research aimed at campaigning the source of alternative income of farmers when oil palm replanting by raising cattle so that the farmer's household still gets a source of income during the palm oil replanting period. The research method used survey method, purposive sampling also used as a technique of collecting sample which is mapping farmers who raise cattle when oil palm replanting. Data needed by using primary and secondary data to obtain business income of cattle. Primary data is obtained directly from farmers and secondary data is obtained from agencies related to this research. Data analysis was conducted by calculating income and BCR. Research results obtained income from cattle was Rp. 4,122,245, - / month with BCR of 1.3. Results of this study found that cattle business when oil palm replanting is feasible because the BCR obtained is greater than one.
\end{abstract}

Key words: cattle, income, replanting, BCR

\begin{abstract}
ABSTRAK
Penelitian bertujuan untuk menemukan Sumber pendapatan petani saat kelapa sawit replanting dengan memelihara ternak sapi agar rumah tangga petani masih memperoleh sumber pendapatan selama masa kelapa sawit replanting. Metode penelitian menggunakan metode survey, pengambilan sampel secara purposive sampling yang dijadikan sampel adalah petani yang memelihara ternak sapi saat kelapa sawit replanting. Data yang diperlukan dengan mengunakan data primer dan sekunder untuk memperoleh pandapatan usaha ternak sapi. Data primer diperoleh langsung dari petani dan data sekunder diperoleh dari instansi dan dinas terkait dengan penelitian ini. Analisa data dilakukan dengan menghitung pendapatan dan BCR. Hasil peneitian diperoleh pendapatan dari ternak sapi sebesar Rp. 4.122.245,-/bulan dengan BCR sebesar 1,3. Dari hasil penelitian ini usaha ternak sapi saat kelapa sawit replanting layak untuk dilakukan karena BCR yang diperoleh lebih besar dari satu.
\end{abstract}

Kata kunci :ternak sapi, pendapatan, replanting, BCR.

\section{PENDAHULUAN}

Pada saat ini di Provinsi Riau seharusnya sudah melakukan replanting perkebunan kelapa sawit, namun banyak petani tidak mau melakukannya karena jika kelapa sawit replanting mereka tidak mempunyai sumber pendapatan keluarga sampai kelapa sawitnya bisa berproduksi hingga umur tiga tahun. Setelah kelapa sawit berumur 25 tahun biasanya akan diganti dengan tanaman yang baru, untuk mempertahankan hidupnya biasanya petani mengusahakan sendiri tanaman dan ternak yang ingin diusahakan sebagai sumber pendapatan keluarga.
Usaha ternak sapi sudah lama dilakukan petani di pedesaan sebagai tabungan dengan pemeliharaan secara tradisional tanpa melakukan pencatatan dan analisa usaha. Penerimaan dan biaya produksi menurut Sugeng (2002), ternak sapi memiliki kemanfaatan lebih luas di dalam masyarakat, sehingga keberadaannya dalam meningkatkan perkembangannya lebih mantap.

Pada saat kelapa sawit replanting ternak sapi dapat dijadikan sumber pendapatan alternatif yang cukup menjanjiakan. Pemeliharaan untuk penggemukan sudah dapat memberikan pendapatan keluarga dalam jangka waktu 4-6 bulan sapi sudah dapat dijual dengan 
pemberian pakan yang ada di sekitar tempat tinggal petani. Kabupaten Siak terdapat 20.305 ekor sapi (Badan Pusat Staitstik Provinsi Riau, 2017), ini merupakan ternak sapi yang dipelihara oleh peternakan rakyat secara tradisional.

Semenjak tahun 2013 sudah $53 \%$ dari total areal perkebunan kelapa sawit di Riau masih menunggu untuk diremajakan (replanting) sering ditunda dalam pelaksanaanya disebabkan berbagai masalah yang dialami petani rakyat. Petani pada umumnya dihadapkan pada masalah permodalan dalam melakukan replanting. Petani tidak mempersiapkan dana untuk replanting, Kendala lain yang dihadapi petani adalah pendapatan petani akan menurun atau tidak ada pendapatan sama sekali. Kecamatan Kerinci Kanan merupakan kecamatan yang memiliki areal tanaman kelapa sawit yaitu 4.632,42 ha dengan total produksi selama 2016 sebesar 17.198,00 ton (Badan Pusat Statistik Provinsi Riau, 2016). Perkebunan kelapa sawit di Kecamatan Kerinci Kanan telah ditanam sejak tahun 1990an. Oleh karena itu sebagian besar dari tanaman kelapa sawit tersebut pada saat ini telah memasuki tahap akhir siklus produksi sehingga perlu dilaksanakan kegiatan replanting.

Pertanian terpadu merupakan sitem pertanian yang mengintegrasikan sub sektor pertanian (tanaman, ternak, ikan) untuk meningkatkan produktivitas sumber daya lahan, kemandirian, kesejahteraan petani secara berkelanjutan. (Siswati dan Nizar, 2014) menyatakan pertanian terpadu dapat menigkatkan pendapatan dan kesejahteraan petani dengan pola tanaman hortikultura dan ternak. Oleh karena itu Tujuan penelitian untuk menemukan sumber pendapatan petani saat kelapa Sawit replanting yaitu dengan memelihara sapi ternak.

\section{MATERI DAN METODE}

Penelitian ini dilaksanakan di Desa Delima Jaya Kecamatan Kerinci Kanan Kabupaten Siak. Penentuan lokasi ini di lakukan secara sengaja (Purposive). Dipilihnya tempat penelitian ini karena di
Desa Delima jaya Kecamatan Kerinci Kanan Kabupaten Siak terdapat petani sawit replanting. Penelitian ini dilaksanakan selama 4 bulan, yakni dari bulan Maret 2018 s/d Juni 2018.

Petani yang dijadikan sampel adalah petani yang memiliki tanaman kelapa sawit yang berumur 20 sampai dengan 25 tahun yang sedang melaksanakan replanting di Desa Delima Jaya Kecamatan Kerinci Kanan Kabupaten Siak. jumlah petani replanting yang memelihara ternak sapi 18 KK. Metode yang digunakan adalah metode sensus, dimana seluruh populasi dijadikan responden. Data yang diambil meliputi data primer dan data sekunder, serta menggunakan teknik Purposive Sampling. Data primer diperoleh dari wawancara langsung terhadap petani replanting.

Data yang telah terkumpul selanjutnya ditabulasikan untuk dianalisis sehingga dapat menjawab sesuai dengan permasalahannya, tujuan penelitian yang telah dirumuskan. Teknik analisis data yang digunakan dalam penelitian ini adalah sebagai berikut. Untuk mengetahui besar pendapatan yang berasal dari dalam dan luar usahatani kelapa sawit menggunakan rumus penerimaan sebagai berikut :

$$
\mathrm{TR}=\mathrm{P} \mathbf{x Q}
$$

Dimana :

$$
\begin{array}{ll}
\mathrm{TR} & =\text { Total Penerimaan }(\mathrm{Rp} / \mathrm{kg}) \\
\mathrm{P} & =\text { Harga Jual Komoditi }(\mathrm{Rp}) \\
\mathrm{Q} & =\text { Jumlah Produksi }(\mathrm{Kg})
\end{array}
$$

(Soekartawi, 2003)

$$
\begin{aligned}
& \text { Rumus B/C Ratio (BCR) } \\
& \text { BCR }=\frac{(\underline{\text { benefit } / R p)}}{(\text { Cost } / \mathrm{Rp})}
\end{aligned}
$$

Dimana :

$$
\begin{array}{lll}
\mathrm{BCR} & = & \text { Benefit Cost Ratio } \\
\mathrm{TR} & = & \text { Total penerimaan (Rupiah) } \\
\mathrm{TC} & = & \text { Total Biaya (Rupiah) }
\end{array}
$$

Secara teoritis dengan $\mathrm{BCR}=1$, artinya usaha tidak mengalami keuntungan ataupun kerugian, jika BCR $<1$, maka usaha 
tersebut rugi. Jika $\mathrm{BCR}>1$ maka usaha memperoleh keuntungan dan dapat dilanjutkan.

\section{HASIL DAN PEMBAHASAN}

Karakteristik petani responden penelitian ini dapat dilihat pada Tabel 1.

Tabel 1. Karakteristik responden

\begin{tabular}{|c|c|c|c|}
\hline \multirow[b]{2}{*}{ No. } & \multirow{2}{*}{ Keterangan } & \multicolumn{2}{|c|}{ Responden } \\
\hline & & Orang & $\%$ \\
\hline \multirow{5}{*}{1} & Umur & & \\
\hline & $40-50$ & 6 & 33,33 \\
\hline & $51-60$ & 9 & 50 \\
\hline & $>60$ & 3 & 16,67 \\
\hline & Jumlah & 18 & 100 \\
\hline \multirow{5}{*}{2} & Tingkat Pendidikan & & \\
\hline & SD & 7 & 38,89 \\
\hline & SLTP & 8 & 44,44 \\
\hline & SLTA & 3 & 16,67 \\
\hline & Jumlah & 18 & 100 \\
\hline \multirow{4}{*}{3} & Jenis Kelamin & & \\
\hline & Perempuan & 1 & 0,56 \\
\hline & Laki-laki & 17 & 94,44 \\
\hline & Jumlah & 50 & 100 \\
\hline \multirow{6}{*}{4} & Pengalaman berusaha tani & & \\
\hline & $\leq 20$ & 1 & 0,56 \\
\hline & $21-26$ & 7 & 38.89 \\
\hline & $27-32$ & 8 & 44,44 \\
\hline & $\geq 33$ & 2 & 11,11 \\
\hline & Jumlah & 18 & 100 \\
\hline
\end{tabular}

Tabel satu Sebagian besar petani responden berusia antara 40 sampai 50 sebanyak (6 orang) 33,33\% sedangkan untuk petani yang berusia 51 sampai 60 tahun berjumlah 9 orang atau $50 \%$ dan $>60$ tahun berjumlah 3 orang atau $16,67 \%$. Tingginya persentase petani yang berusia diantara 51 sampai 60 tahun masih didominasi oleh petani berpengalaman. Hal ini disebabkan petani di Desa Delima Jaya adalah transmigrasi dari Pulau Jawa sudah berumur di atas 40 tahun. Seseorang yang berada pada usia produktif akan menghasilkan produktivitas lebih tinggi dari pada mereka yang berada di luar usia produktif.

Tingkat pendidikan formal responden sebagian besar sampai pendidikan SLTA yaitu berjumlah 3 orang atau $16,67 \%$, untuk tingkat SLTP berjumlah 8 orang atau 44,44 $\%$, sebagian besar pendidikan petani masih
SLTP sedangkan untuk tingkat pendidikan SD berjumlah 7 orang atau 38,89\%. Tingkat pendidikan yang lebih tinggi akan memudahkan seseorang atau masyarakat untuk menyerap informasi, pendidikan formal membentuk nilai bagi seseorang terutama dalam menerima hal baru (Suhardjo, 2007).

Sebagian besar responden dengan jumlah 17 orang atau 94,44\% berjenis kelamin Laki-laki. Banyaknya responden laki-laki menunjukkan responden sebagai petani umumnya merupakan seorang kepala keluarga. Selain itu juga terdapat responden wanita dengan jumlah satu orang atau $0,56 \%$ hal ini istri ikut terlibat membantu suaminya dalam usahatani.

Responden dalam penelitian ini mempunyai pengalaman sudah cukup lama dalam berusahatani. Persentase jumlah 
petani yang memiliki pengalaman kurang dari 20 tahun berjumlah satu orang atau 0,56 $\%$. Persentase jumlah petani yang memiliki pengalaman antara $21-26$ tahun berjumlah 7 orang atau $38,89 \%$. Persentase jumlah petani yang mimiliki pengalaman antara 27 32 tahun mencapai 8 orang atau 44,44\%. Sedangkan persentase jumlah petani yang memiliki pengalaman lebih dari 33 tahun berjumlah 2 orang atau $11,11 \%$. Menurut Soekartawi (2006), pengalaman berusahatani yang cukup lama menjadikan petani lebih matang dan lebih berhati-hati dalam mengambil keputusan terhadap usaha taninya.

Pendapatan Saat Kelapa Sawit Replanting Replanting kelapa sawit merupakan suatu keharusan yang dilakukan oleh petani karena umur kelapa sawit sudah berumur 25 tahun, jika tidak maka produksi menurun dan biaya semakin besar sehingga tidak produktif lagi. Hasil penelitian menemukan banyak petani yang harus melakukan replanting tetapi tidak melaksanakannya karena tidak punya pendapatan lagi untuk keluarganya sedangkan kebutuhan selalu meningkat. Biaya replanting cukup besar petani tidak menyediakan dana untuk itu. Dari pertanian terpadu saat masa replanting petani ada yang menanam kelapa sawit di lahan yang lain untuk sumber pendapatan keluarga tetapi dengan luas yang lebih kecil. Selain kelapa sawit petani memelihara ternak sapi sebagai sumber pendapatan keluarga.

Rata-rata pemilikan ternak sapi sebanyak 7.35 unit ternak perpetani, Sebagai sumber pendapatan keluarga pendapatan ternak sapi sebesar Rp 4.122.245/bulan. Hal ini lebih tinggi dari UMR Kabupaten Siak tahun 2018 sebesar Rp. 2.551.000/bulan. Krisna dan Manshur (2006) menyatakan bahwa tinggi rendahnya pendapatan yang dipengaruhi oleh jumlah ternak yang dipelihara, semakin banyak ternak yang dipelihara semakin banyak keuntungan yang akan diterima oleh peternak. Berarti dengan memelihara ternak sapi saat kelapa sawit replanting merupakan salah satu alternatif sumber pendapatan yang cukup menjanjikan.
Ini lebih kecil dari pendapatan pertanian terpadu (Siswati, 2012). Pendapatan pertanian terpadu Rp. 6.900 .000 /bulan lebih tinggi dari UMR Provinsi Riau Rp. 2.300.000 /bulan, Juga lebih tinggi dari pendapatan usahatani satu komoditi. Lebih lanjut lagi, penerimaan petani usahatani terpadu $\mathrm{Rp}$. 3.693.000/bulan ini lebih rendah dari saat petani telah menerapkan pertanian terpadu dengan konsep zero waste dimana usahatani telah memanfaatkan limbah dan mengurangi biaya produksi (Siswati and Nizar, 2014). Oleh Karena itu hal ini dapat diterapkan bagi petani yang kelapa sawit replanting sebagai sumber pendapatan keluarga.

Tabel 2. Pendapatan ternak sapi

\begin{tabular}{llr}
\hline No & \multicolumn{1}{c}{ Uraian } & $\begin{array}{c}\text { Jumlah } \\
\text { (Rp/peternak/ } \\
\text { bulan) }\end{array}$ \\
\hline 1 & Penerimaan & \\
& Penjualan sapi & $\begin{array}{r}17.465 .015,- \\
365.250,-\end{array}$ \\
& Penjualan kotoran sapi & $17.830 .265,-$ \\
\hline & Total Penerimaan & $12.250 .000,-$ \\
\hline 2 & Biaya tidak tetap & $110.000,-$ \\
& Bibit & $258.000,-$ \\
& Tenaga kerja & $12.618 .000,-$ \\
& Pakan & $875.000,-$ \\
& Total biaya tidak tetap & $215.000,-$ \\
\hline 3 & Biaya tetap & $1.090 .000,-$ \\
& Kandang & $13.708 .000,-$ \\
& Penyusutan peralatan & $4.122 .245,-$ \\
\hline & Total biaya tetap & 1,3 \\
\hline 4 & Total biaya ( 2+3) & \\
\hline 5 & Pendapatan 1- (2+3) &
\end{tabular}

Pada tabel 2 diatas, pendapatan dari usaha ternak sapi saat kelapa sawit replanting sebesar Rp 4.122.245,-/bulan. Ini disebabkan oleh usaha ternak sapi dapat memperoleh pendapatan lebih besar karena hasil penjualan ternak sapi selalu lebih tinggi harganya sesuai harga pasar saat ini dan masih belum terpenuhi permintaan kebutuhan sapi untuk memenuhi kebutuhan daging di Kabupaten Siak khususnya Provinsi Riau umumnya. Benefit Cost Ratio dari usaha ternak sapi sebesar 1,3 berarti 
usahanya layak untuk dilanjutkan sebagai sumber pendapatan keluarga.

\section{KESIMPULAN}

Pendapatan peternak sapi di saat kelapa sawit replanting Rp. 4.122.245,/bulan dengan BCR sebesar 1,3.

\section{SARAN}

Saat kelapa sawit replanting dapat dilakukan usaha ternak sapi dan untuk dapat memperoleh pendapatan lebih besar maka peternak harus memelihara sapi lebih banyak lagi .

\section{UCAPAN TERIMAKASIH}

Terimakasih penulis aturkan kepada KEMENRISTEK DIKTI yang telah mendanai penelitian Penelitian terapan Unggulan Perguruan Tinggi tahun 2018 [Nomor : 007/ KONTRAK PENELITIAN /K10/ 2018]. Juga ucapan yang sama kepada Universitas Lancang Kuning dan Lembaga Peneitian dan Pengabdian pada Masyarakat Universitas Lancang Kuning juga Dekan Fakultas Pertanian yang telah menfasilitasi penelitian ini dan memberikan sumbangan pemikiran. Tidak lupa terimakasih kepada petani dan dinas perkebunan Kabupaten Siak, PPL Kecamatan Kerinci Kanan yang banyak memberi informasi dan data pada penulisan ini.

\section{DAFTAR PUSTAKA}

Ayob, M. A. and Kabul, M.H., 2012. Cattle integration in oil palm plantation through systematic management. In International Seminar on Animal Industry.

Badan Pusat Staitstik Provinsi Riau. 2017. Riau dalam angka. Badan Pusat Statistik. Pekanbaru.

Badan Pusat Statistik Provinsi Riau. 2016. Badan Pusat Statistik Provinsi Riau. Pekanbaru.
Jalaludin, S. 1996. Integrated animal production in the oil palm plantation. In Second FAO electronic conference on tropical feeds: livestock feed resources within integrated farming Systems. 9 : 37-43.

Krisna, R. dan Manshur. 2006. Tingkat kepemilikan dan biaya usaha dengan pendapatan peternak sapi potong di Kabupaten Sukabumi Provinsi Jawa Barat. Jurnal Aplikasi Manajemen. 12 (2): 295-305.

Lam, M. K., K. T. Tan, K. T. Lee, and A. R. Mohamed. 2009. Malaysian palm oil: Surviving the food versus fuel dispute for a sustainable future. Renewable and Sustainable Energy Reviews. 13 (6-7): 1456-1464.

Latif, J. and M. N. Mamat. 2002. A financial study of cattle integration in oil palm plantations. Oil Palm Industry Economic Journal. 2(1): 34-44.

Qiyanah, M. 2017. Analisis Pendapatan Peternakan Sapi potong di Desa Mattirowalie Kecamatan Tanete Riaja Kabuapten Barru. Skripsi Fakultas peternakan Universitas Hasanudin. Makasar.

Siswati, L. 2012. Pola pertanian terpadu ternak dan tanaman hortikultura di Kota Pekanbaru. Jurnal Peternakan. 9(2): $75-82$

Siswati, L., dan R. Nizar. 2014. Model pertanian terpadu tanaman hortikultura dan ternak sapi untuk meningkatkan pendapatan petani. Jurnal Peternakan Indonesia. 14 (2): 379-384.

Soekartawi. 2003. Prinsip Dasar Ekonomi Pertanian. Rajawali Press, Jakarta

Suhardjo. 2007. Pengaruh Tingkat Pendidikan. Jakarta : Sinar Harapan.

Sugeng, B. 2002. Sapi Potong, Ed. Revisi. Penebar Swadaya . Jakarta. 